Clinical Allergy, 1982, Volume 12, pages 577-586

\title{
Release of histamine from leucocytes and its determinants in vitro in relation to bronchial responsiveness to inhaled histamine and exercise in vivo
}

\author{
H. J. NEIJENS, H. C. RAATGEEP, H. J. DEGENHART and \\ K. F. KERREBIJN
}

Department of Paediatrics, Sub-department of Respiratory Diseases, Erasmus
University, Medical School, Sophia Children's Hospital, Rotterdam, The Netherlands

(Received 6 October 1981; accepted for publication 6 January 1982)

\begin{abstract}
Summary
The hypothesis studied is that increased responsiveness in asthma is not limited to the airways. Forty asthmatic children were analysed for their bronchial responsiveness (BR) to exercise. Twenty patients revealed bronchial obstruction after exercise while the remainder did not. These observations were compared with the responsiveness of leucocytes, which was determined by their histamine 'releasability'. Twenty healthy children served as controls. Release of histamine induced by calcium ionophore-aided calcium influx was significantly higher in both groups of asthmatics than in the healthy children $(P<0.005)$. Similar findings were obtained by induction of microtubule aggregation due to deuterium oxide $\left(\mathrm{D}_{2} \mathrm{O}\right)$. The S-shaped dose-response relationship with $\mathrm{D}_{2} \mathrm{O}$ was shifted to the left in the patients with $\mathrm{BR}$ to exercise compared to patients without $(P<0.025)$. The slope was increased in both patient groups compared with the healthy children $(P<0.01)$. It is concluded that the mean 'releasability' of histamine release due to both stimulants correlated well $(P<0 \cdot 01)$. This suggests that the 'releasability' is determined by the responsiveness of the microtubules. This may also apply to allergen-induced histamine release, as was revealed from studies with anti-IgE. The differences in histamine release found in relation to BR due to exercise were also present if the patients were divided according to BR due to histamine. A significant relationship existed between the degree of $\mathrm{BR}$ to histamine and the responsiveness of the microtubules $(P<0.02)$.
\end{abstract}

\section{Introduction}

Increased bronchial responsiveness (BR) can be observed in many asthmatic patients (Boushey et al., 1979). Increased BR is characterized by the occurrence of bronchial obstruction due to various stimuli at a dose which does not have such a result in subjects with normal responsiveness (Kiviloog, 1973; Neijens et al., 1979).

Correspondence: H. J. Neijens and K. F. Kerrebijn, Sophia Children's Hospital, Gordelweg 160, 3038 GE Rotterdam, The Netherlands. 
Abnormal responses in various systems, such as lysozymatic release from leucocytes (Busse et al., 1979) and pupillary reflexes (Smith, Shelhamer \& Kaliner, 1980 ) has been reported in relation to asthma. We have studied histamine release from basophil leucocytes to investigate cell dysfunction in asthmatic children with increased BR. In a previous study we (Neijens et al., 1980) and others (Findlay \& Lichtenstein, 1980 ) found a correlation between the mean histamine release from leucocytes and the degree of BR. Our present study investigates which part of the release process dysregulation involves. The influx of calcium into the cells was stimulated with the calcium ionophore A 23187 (Siragarian et al., 1975). This may increase the release of histamine from basophil leucocytes. The influence of zinc on the calcium-induced histamine release has been reported by Kazimierczak and Máslinśki (1974). Microtubules are thought to be important in the extraction of mediator-containing granules which are necessary for the release of mediators (Padawar, 1979). The effects of the induction of microtubular aggregation due to deuterium oxide $\left(\mathrm{D}_{2} \mathrm{O}\right)$ (Gillespie \& Lichtenstein, 1972) are reported.

\section{Methods}

\section{Design of the study}

The study was carried out on 2 consecutive days. On the first day blood was collected by a venepuncture and the provocation dose of inhaled histamine was determined. On the second day an exercise test was performed.

\section{Patients}

The asthmatic children were selected from the out-patient clinic of the Sophia Children's Hospital in Rotterdam, based on the following criteria: (1) The patients had to be in a stable clinical condition for at least 3 weeks prior to the study; (2) the patients could perform lung function tests in a reproducible way; and (3) all drugs were withdrawn at least 2 days before the study. None of the patients was treated with hyposensitization therapy.

The healthy children were without present or previous symptoms of chronic rhinitis, hayfever or eczema and without bronchial obstruction after exercise.

\section{Measurement of histamine release}

Twenty millilitres of venous blood was taken with the patient at rest at 8.30 a.m. From this a 1-ml suspension of leucocytes was prepared and incubated with and without one of the following agents: (1) $\mathrm{D}_{2} \mathrm{O}, 20,40,60,70$ and $80 \%$ in combination with cytochalasine $\mathrm{E}\left(2 \cdot 10^{-5} \mathrm{M}\right)$, with appropriate $\mathrm{pH}$ correction; (2) calcium ionophore A $23187,0.56 \times 10^{-6} \mathrm{M}\left(0.3 \mathrm{mg} .1^{-1}\right)$ and $2.80 \times 10^{-6} \mathrm{M}\left(1.5 \mathrm{mg} .1^{-1}\right)$ with and without $\mathrm{Ca}^{2+}\left(10^{-3} \mathrm{M}\right)$ or $\mathrm{Zn}^{2+}\left(\mathrm{ZnSO}_{4} 1 \cdot 5 \cdot 10^{-5} \mathrm{M}\right)$; (3) anti-IgE, $20 \mu \mathrm{l}$ of a $400 \mathrm{iu} / \mathrm{ml}$ solution (Behringwerke) in combination with $\mathrm{Ca}^{2+}\left(10^{-3} \mathrm{M}\right)$.

Release of histamine was measured after $1 \mathrm{hr}$ incubation, using the method of May et al. (1970). All measurements were done in triplicate and the values given are the average of three. The leucocytes and basophils were counted in the samples, according to the method of Moore and James (1953).

\section{The bronchial responsiveness to histamine and to exercise}

This was determined as described previously (Neijens et al., 1980). 
The patients were divided according to their reaction after exercise: patients with a bronchial obstruction after exercise, i.e. a decrease in the forced expiratory volume in the first second $\left(\mathrm{FEV}_{1}\right)$ of $>15 \%$ from baseline and those without this phenomenon. The groups were indicated as bronchial responsiveness to exercise positive (BRE +) and negative (BRE -) respectively. Twenty-two healthy children formed the third group. The patient groups comprised twenty children, and all were comparable with regard to age and sex. All the subjects and their parents were fully informed about the methods and the aims of the study before they gave their consent.

\section{Statistical analysis}

The differences in results between the three groups were analysed with a test for multiple comparisons (Conover, 1980). Correlations of the parameters were calculated according to Spearman. The regression lines were determined using the median values of the regression equations of each pair of subjects, according to the method of Nimmo
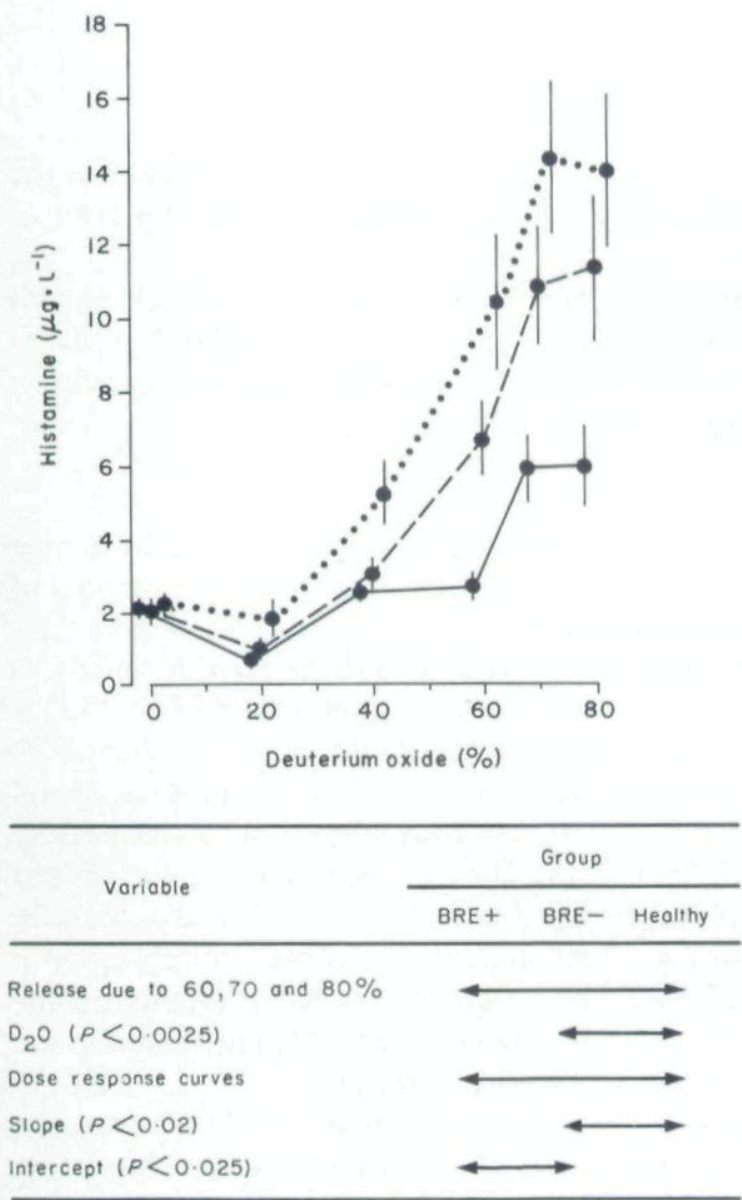

Fig. 1. Histamine release from leucocytes in vitro as a function of the percentage of deuterium oxide. The results are expressed in mean \pm s.e. mean for each of the three group of subjects. $\cdots ;$ Asthmatics, bronchial responsiveness to exercise $+;---$, asthmatics bronchial responsiveness to exercise $-;-$, healthy controls. 
Table 1.* (No significant relationship exists between number of cells and amount of histamine release)

\begin{tabular}{|c|c|c|c|c|}
\hline \multirow[b]{2}{*}{ Group } & \multirow[b]{2}{*}{$n$} & \multicolumn{2}{|c|}{ Number of cells } & \multirow{2}{*}{$\begin{array}{r}\text { Histamine release due } \\
\text { to } \mathrm{D}_{2} \mathrm{O} \\
\text { (median response) } \\
\left(\mu \mathrm{g} \mathrm{.} \mathrm{I}^{-1}\right) \ddagger\end{array}$} \\
\hline & & $\begin{array}{r}\text { Leucocytes } \dagger \\
\left(10^{3} / \mu \mathrm{l}\right)\end{array}$ & $\begin{array}{r}\text { Basophils } \\
(\mu \mathrm{l})\end{array}$ & \\
\hline $\mathrm{BRE}+$ & 20 & $\begin{array}{r}24 \cdot 9 \\
(8 \cdot 9-56 \cdot 3)\end{array}$ & $\begin{array}{r}26 \cdot 0 \\
(10 \cdot 0-74 \cdot 0)\end{array}$ & $\begin{array}{r}6.4 \\
(1.7-23.0)\end{array}$ \\
\hline BRE - & 20 & $\begin{array}{r}26 \cdot 2 \\
(5 \cdot 2-44 \cdot 5)\end{array}$ & $\begin{array}{r}28 \cdot 5 \\
(3 \cdot 0-77 \cdot 0)\end{array}$ & $\begin{array}{r}4 \cdot 5 \\
(0 \cdot 8-15 \cdot 3)\end{array}$ \\
\hline Healthy children & 20 & $\begin{array}{r}21 \cdot 4 \\
(8.9-42 \cdot 5)\end{array}$ & $\begin{array}{r}27 \cdot 5 \\
(6 \cdot 0-70 \cdot 0)\end{array}$ & $\begin{array}{r}2.8 \\
(1.4-5.3)\end{array}$ \\
\hline
\end{tabular}

\footnotetext{
* All results are expressed as median value with extreme values in parentheses.

+ In the leucocyte suspension.

$\ddagger$ Histamine release is the median response after all doses of $\mathrm{D}_{2} \mathrm{O}$ for each patient.
}

and Atkins (1979). The slopes and intercepts of these lines were compared with the patient groups using Wilcoxon tests. The $5 \%$ level was considered as the level of significance.

The steepness and the parallel shift of the individual regression lines is expressed as a single value by determination of the 'median response', i.e. the histamine release which is the median value of all responses after each of the sequential $\mathrm{D}_{2} \mathrm{O}$ series in an individual. The median $\mathrm{D}_{2} \mathrm{O}$ response is used in Table 1, Figs 2 and 3 .

\section{Results}

The median values of the numbers of leucocytes and basophils and the histamine release are shown in Table 1. No significant relationship exists between the number of these cells and the degree of histamine release.

In Fig. 1 the mean histamine released by sequential $\mathrm{D}_{2} \mathrm{O}$ concentrations is illustrated for each group of subjects. The mean release with 60,70 and $80^{\circ} \mathrm{D}_{2} \mathrm{O}$ is significantly higher in the patient groups than in the healthy group $(P<0.0025)$. The dose response relationship is evaluated by the regression line of the responses at 40 and $60 \%$. The slope in groups BRE + and BRE - is significantly steeper than in the healthy individual group $(P<0 \cdot 01)$. Between $\mathrm{BRE}+$ and $\mathrm{BRE}-$ patients the slopes do not differ significantly, but the intercepts of their regression lines with the $y$-axis do differ significantly $(P<0.025)$. It is therefore concluded that the mean dose response curve in asthmatic children with an increased BRE was shifted to the left compared to the asthmatic children without BRE. The regression lines of the asthmatic children are rotated anti-clockwise compared to that of the healthy subjects.

The mean release of histamine with the calcium ionophore A 23187 alone or combined with calcium or zinc is shown in Fig. 2. In all groups the release of histamine increases markedly after the addition of calcium to the calcium ionophore. There is no significant difference in release with 0.3 and $0.5 \mathrm{mg} \mathrm{.} 1^{-1}$ calcium ionophore. The mean release by the calcium ionophore plus calcium is greater in the patients with BRE than without BRE $(P<0.005)$ and than in the healthy children $(P<0.005)$. The difference 


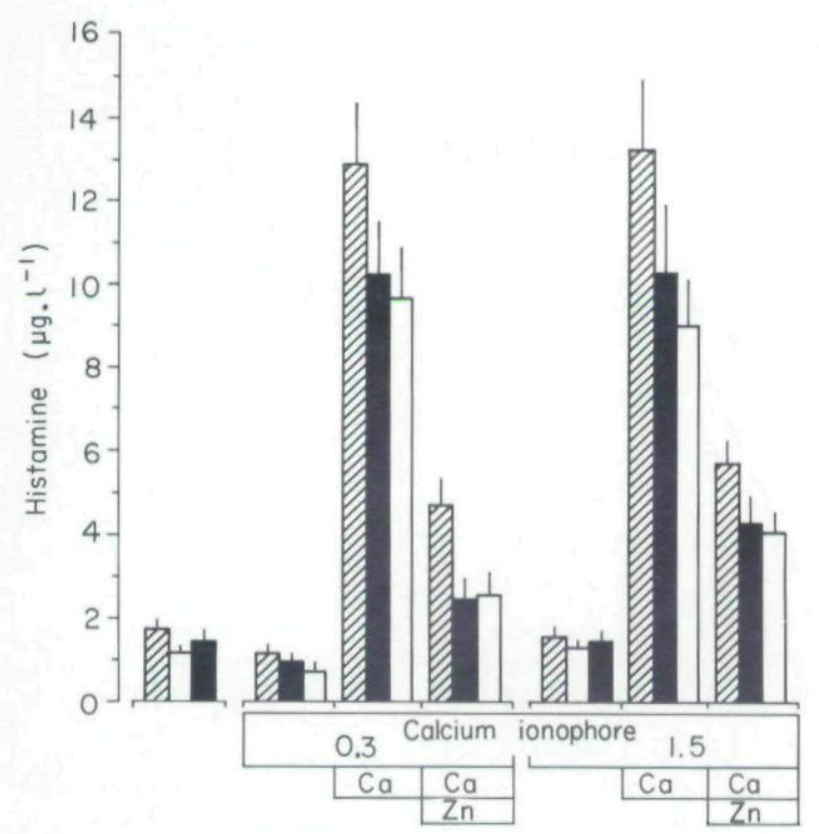

Fig. 2. Mean histamine release ( \pm s.e. mean) from leucocytes in vitro with and without various agents in three groups of subjects. Results after the calcium ionophore with calcium are significantly higher in $\mathrm{BRE}+$ subjects than in BRE - subjects $(P<0.005)$ and healthy children $(P<0.005)$. These differences in the presence of zinc are also significant $(P<0.01)$. $\square$, Asthmatics, bronchial responsiveness to exercise + ; $\mathbf{m}$, asthmatics, bronchial responsiveness to exercise $-; \square$, healthy controls.

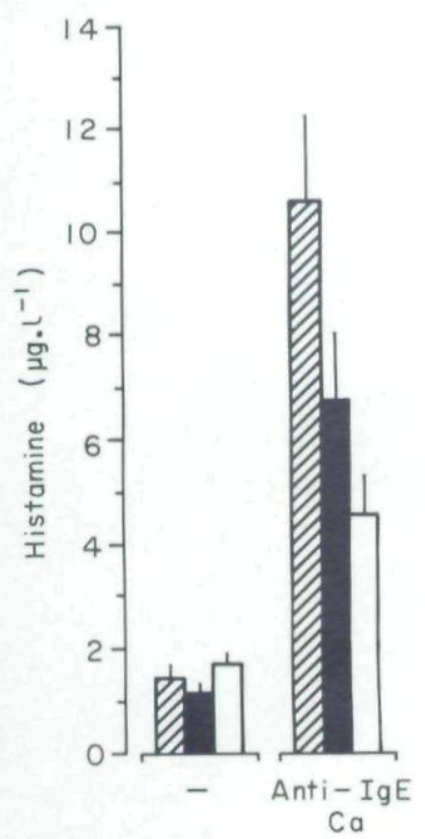

Fig. 3. Mean histamine release ( \pm s.e. mean) from leucocytes in vitro with and without anti-IgE plus calcium in three groups of subjects. The results are significantly different between all groups $(P<0 \cdot 05)$. Key as for Fig. 2. 


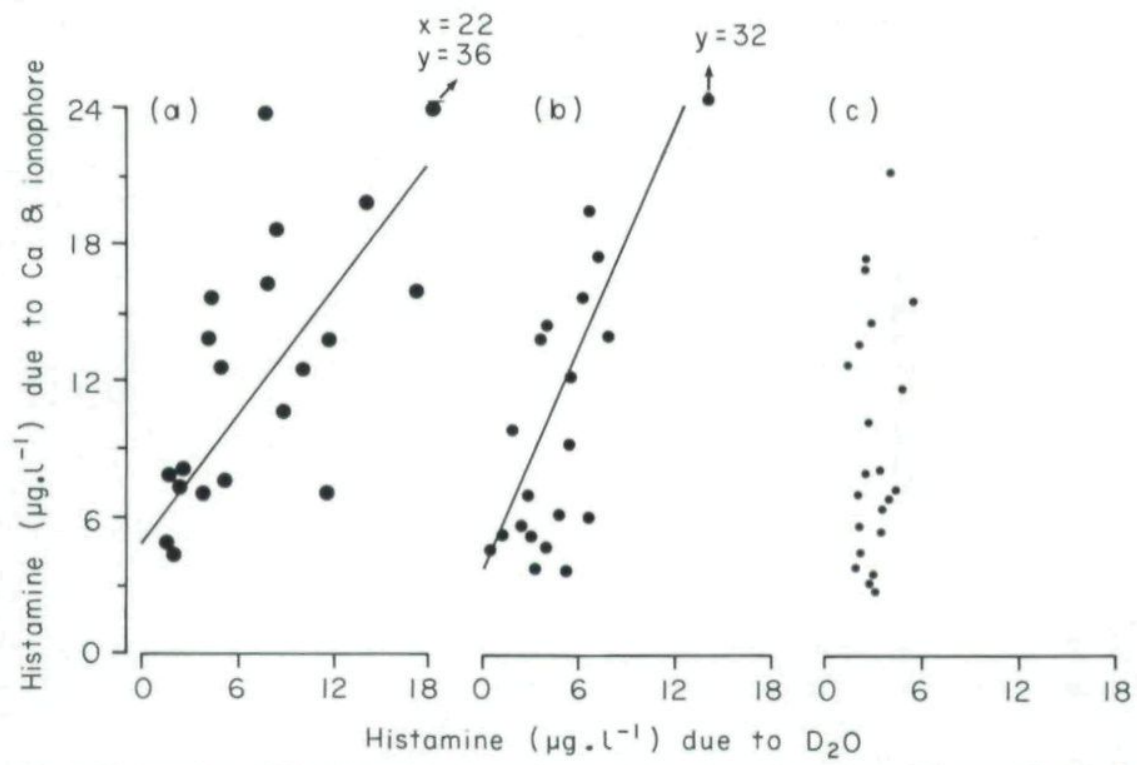

Fig. 4. Comparison of the histamine release due to calcium ionophore plus calcium (calcium influx) and that due to $\mathrm{D}_{2} \mathrm{O}$ (median response) in three groups of subjects: (a) asthmatics $\mathrm{BRE}+$; (b) asthmatics $\mathrm{BRE}-$; and (c) healthy subjects. The relationships are significant in groups of BRE + and BRE - subjects $(P<0 \cdot 01)$. In the healthy children a correlation cannot be expressed because of mathematical reasons. The slope of the median regression line is significantly steeper in the BRE - patients than in the BRE + patients $(P<0.02)$.

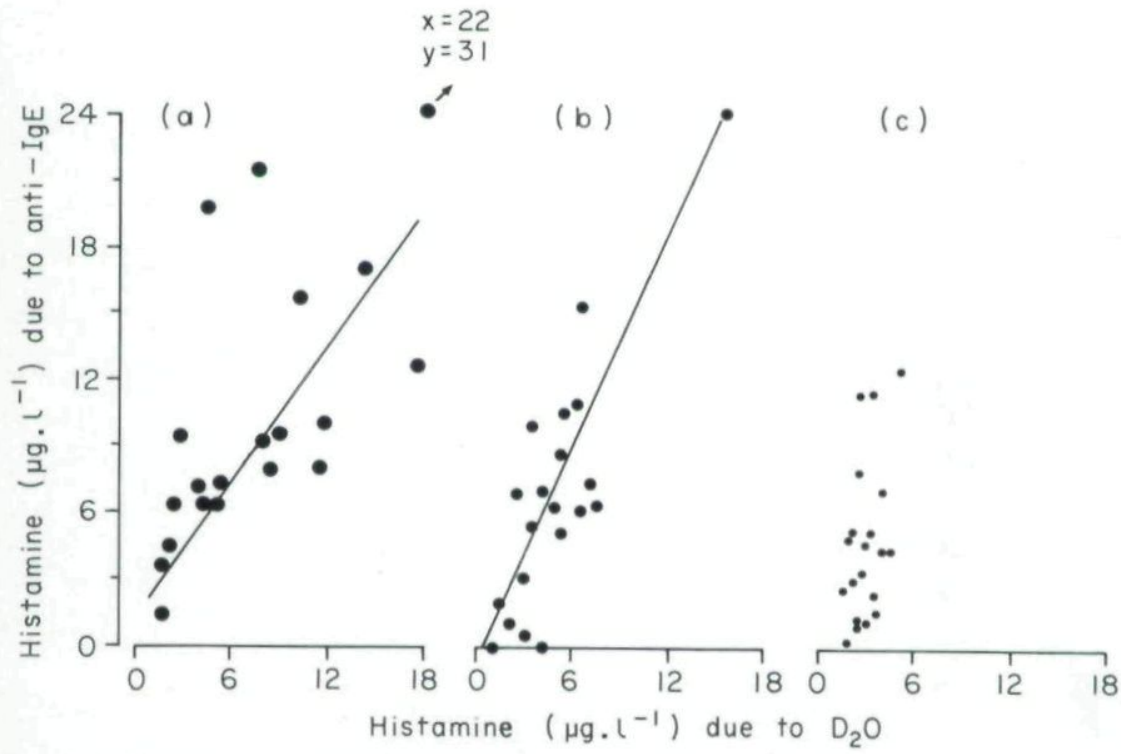

Fig. 5. Comparison of the histamine release due to anti-IgE and that due to $\mathrm{D}_{2} \mathrm{O}$ (median response) in three groups of persons: (a) asthmatics BRE +; (b) asthmatics BRE - ; and (c) healthy children. The relationships are significant in the patient groups $(P<0.01)$, but not in the healthy children (see caption Fig. 2). The slope of the median regression line is significantly steeper in the BRE - than in the BRE + patients $(P<0 \cdot 01)$. 
between the release in the patients without BRE and the healthy controls does not reach significance. If zinc is added to the combination of calcium ionophore and calcium the histamine release decreases. However, the differences between the groups persist $(P<0 \cdot 01)$.

Figure 3 shows the anti-IgE induced release of histamine for the three groups. It is highest in the patients with BRE, intermediate in those without BRE and lowest in the healthy children. The differences between all groups are significant at the $5 \%$ level.

For each group the histamine release after the calcium ionophore plus calcium and the release after $\mathrm{D}_{2} \mathrm{O}$ are compared in a xy-graph (Figure $4 \mathrm{a}, \mathrm{b}, \mathrm{c}$.). The correlation is significant $(P<0.01)$ in both groups of patients, but not in the healthy children. The slopes of the regression lines in the patient groups differ significantly $(P<0.02)$, decreasing with a higher bronchial responsiveness.

Figure 5 shows the correlation between the histamine release after $\mathrm{D}_{2} \mathrm{O}$ and anti-IgE as in Fig. 4. The correlation is again significant in the patient groups $(P<0 \cdot 01)$, but not in the healthy children. The difference between the slopes in the patient groups with and without $\mathrm{BRE}$ is significant $(P<0 \cdot 01)$, decreasing with a higher bronchial responsiveness.

The patients can also be divided into two classes by their histamine provocation doses, as a measure of BR to inhaled histamine. This in vivo measure of BR is related to

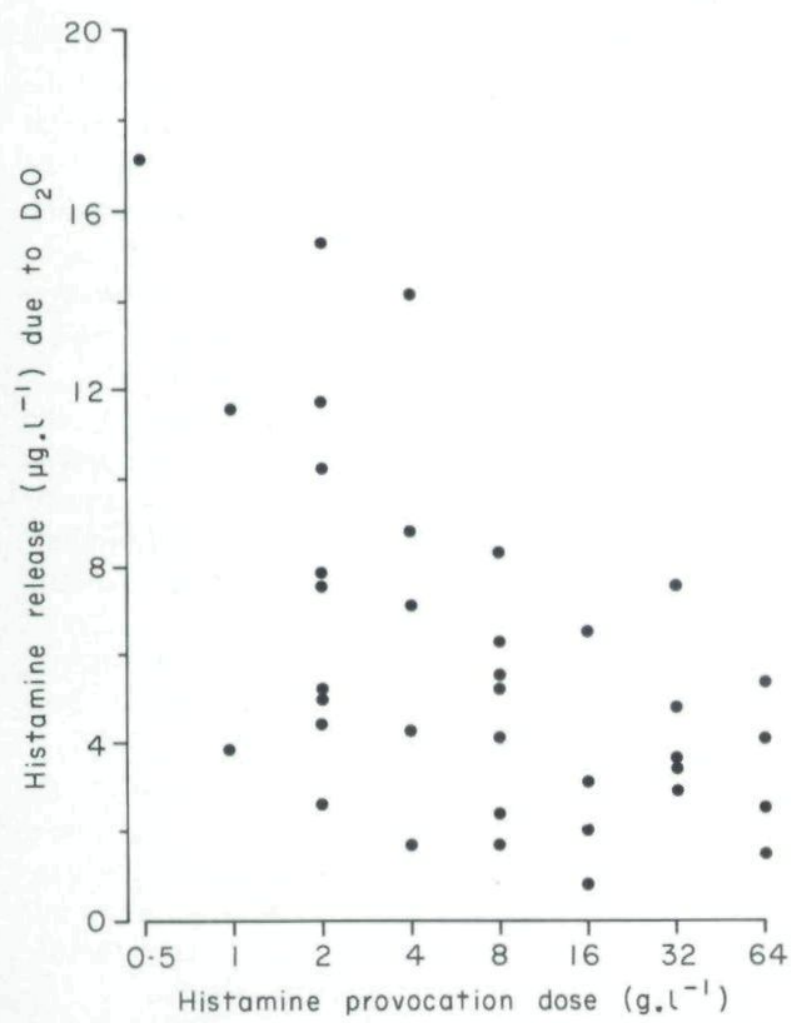

Fig. 6. Relationship for each patient between the bronchial responsiveness to histamine (histamine provocation dose) and the histamine release in vitro due to $\mathrm{D}_{2} \mathrm{O}$, median responses. The relationship is significant (Spearman, $\rho=-0.40, P<0.02$ ). 
the release of histamine in vitro. The relationships approximate to those found in the case of BR to exercise (not shown). In Fig. 6 the histamine provocation doses and the $\mathrm{D}_{2} \mathrm{O}$ induced histamine release are compared as continuous variables. They are significantly related $(P<0 \cdot 02)$.

\section{Discussion}

In a suspension of leucocytes the release of histamine without activation of the IgE-receptor can be induced by influx of calcium (by means of a calcium ionophore) and also by activation of the microtubular aggregation (by $\mathrm{D}_{2} \mathrm{O}$ ). This agrees with results in other studies (Gillespie \& Lichtenstein, 1968; Findlay \& Lichtenstein, 1980). The histamine release is greater in asthmatics with BRE than those without BRE, and the release in asthmatics is greater than in healthy subjects. This indicates that an increase in $\mathrm{BR}$ is associated with an increase in the releasability of basophil leucocytes.

Relatively low concentrations of zinc which are in the range of those found in normal plasma, inhibit the calcium-induced histamine release. Probably it effects the first part of the mediator releasing process, the influx of calcium, as the mediator release after the activation of the microtubules is not inhibited by zinc (preliminary observations). A change in the plasma zinc concentration may influence mediator release in vivo, but there is as yet no data confirming this suggestion. The responsiveness of the total intracellular sequence may be determined by the degree to which the microtubules can be activated.

The influx of calcium leads to the release of mediators via a series of events (Lichtenstein, 1975). The histamine release after stimulation of an initial step in the sequence (calcium influx) correlates highly with that due to the activation of a step later on in the sequence (induction of microtubular aggregation). It seems that the responsiveness of the total intra-cellular sequence is determined by the degree to which the microtubules can be activated.

The histamine release after anti-IgE is related to the $\mathrm{D}_{2} \mathrm{O}$ induced release in a similar way. This indicates that at least in part the allergen-induced mediator release is also determined by the degree to which the microtubules can be stimulated.

It is widely accepted that the activity of the microtubules is regulated by the intracellular cyclic AMP concentration (Mongar \& Foreman, 1979). However, cyclic AMP may well have other effects on intracellular processes which lead to mediator release (Smolen, Korzak \& Weissman, 1980). Therefore, although, the 'releasability' seems to be determined to a large extent by the state of the aggregation of the microtubules, this may not be the only factor involved.

Besides the dysregulation of the mechanisms which determine the bronchial diameter and the increased responsiveness of basophilic leucocytes, dysregulation of other systems is also described in asthma. Hyper-responsiveness of the pupillary reflexes was found in asthmatic patients in relation to a cholinergic agent (Smith et al., 1980 ) and to an $\alpha$-sympathetic agonist (Henderson et al., 1979). The latter study also showed a hyper-responsiveness of the cutaneous blood flow to an $\alpha$-sympathetic agonist in asthmatics. In leucocytes, hypofunction of receptors which counteract mediator release, such as the $\beta$-sympathetic (Lemanske et al., 1980) and the histamine and prostaglandin $E_{1}$ receptors (Busse et al., 1980) was found in asthmatics. The bronchial smooth muscle had a greater contractibility in asthmatics than in normal subjects (Stephens et al., 1980). The cyclic AMP concentration in bronchial smooth muscle was found to be depressed in relation to the presence of asthma in dogs (Rinard 
et al., 1979). Thus, in asthma, a generalized dysregulation seems to be present, which is apparent both inside and outside the respiratory system.

This study leads to the conclusion that the dysregulation which exists in basophilic leucocytes in association with a dysregulation of bronchial responsiveness, may be determined by an indentical factor, such as the level of the cyclic nucleotides. Studies to investigate this in more detail are in progress.

\section{Acknowledgment}

This work was supported by a grant from the Netherlands Asthma Foundation (Project No. 79.31). The authors wish to thank Prof. R. van Strik for statistical advice, Miss I. Dekker for performing the basophil counts, Dr J. Mason for help in correcting our English and Miss A. de Reus for typing the manuscript.

\section{References}

Boushey, H.A., Holtzman, M.J., Sheller, J.R. \& Nadel, J.A. (1980) Bronchial hyperreactivity (state of art). American Review of Respiratory Disease, 121, 389.

Busse, W.W., ANDERSON, C.L., Dick, E.C.D. \& WARSChauer, D. (1980) Reduced granulocyte response to isoproterenol, histamine, and prostaglandin $\mathrm{E}_{1}$, after in vitro incubation with rhinovirus 16. American Review of Respiratory Disease, 122, 641.

Conover, W.J. (1980) Practical Non-parametric Statistics, 2nd ed. pp. 171-178. Wiley \& Sons, New York. Findlay, S.R. \& Lichtenstein, L.M. (1980) Basophil releasability in patients with asthma. American Review of Respiratory Disease, 122, 53.

Gillespie, E. \& Lichtenstein, L.M. (1972) Histamine release from human leucocytes. Studies with deuterium oxide, colchicine and cytochalasin B. Journal of Clinical Investigation, 51, 2941.

Henderson, W.R., Shelhamer, J.H., Reingold, D.G., Smith, L.J., Evans, R. \& Kaliner, M. (1979) Alpha-adrenergic hyperresponsiveness in asthma. Analysis of vascular and pupillary responses. New England Journal of Medicine, 300, 642.

KAZIMIERCZAK, W. \& MAŚLINŚKi, C. (1974) The effect of zinc ions on selective and non-selective histamine release in vitro. Agents and Actions, $4,1$.

Kiviloog, J. (1973) Variability of bronchial reactivity to exercise and methacholine in bronchial asthma. Scandinavian Journal of Respiratory Disease, 54, 359.

Lemanske Jr, R.F., Anderson, C., Braun, S., Skatrud, J. \& Busse, W.W. (1980) Impaired in vitro $\beta$-adrenergic granulocyte response in chronic obstructive pulmonary disease. American Review of Respiratory Disease, 122, 213.

LichTENSTEIN, L.M. (1975) Sequential analysis of the allergic response: cyclic AMP, calcium and histamine. International Archives Allergy Applied Immunology, 49, 143.

May, C.D., Lyman, M., Alberto, R. \& Cheng, J. (1970) Procedures for immunochemical study of histamine release from leucocytes with small volume of blood. Journal of Allergy and Clinical Immunology, 58, 432.

Mongar, J.L. \& Foreman, J.C. (1979) Control of histamine secretion. In: The Mast Cell: Its Role in Health and Disease (eds J. Pepys and A. M. Edwards) p. 30. Pitman Medical, London.

MOORE, J.E. \& JAMes, G.W. (1953) Proceedings of the Society for Experimental Biology, New York, 82, 601.

Neijens, H.J., Degenhart, H.J., Raatgezp, H.C. \& Kerrebun, K.F. (1979) Study of the significance of bronchial hyperreactivity in the bronchus obstruction after inhalation of cat dander allergen. Journal of Allergy and Clinical Immunology, 67, 507.

Neijens, H.J., Degenhart, H.J., RaAtgeep, R. \& Kerrebijn, K.F. (1980) The correlation between increased reactivity of the bronchi and of mediator releasing cells in asthma. Clinical Allergy, 10, 535.

Nimmo, I.A., A tKıns, G.L. (1979) The statistical analysis of non-normal (real?) data. Trends in Biochemical Sciences, 4, 236.

PADAWAR, J. (1979) Mast cell structure implications for normal physiology and degranulation. In: The Mast Cell: Its Role in Health and Disease (eds J. Pepys and A. M. Edwards) p. 1. Pitman Medical, London.

Rinard, G.A., Rubinfeld, A.R., Brunton, L.L. \& Mayer, S.E. (1979) Depressed cyclic AMP levels in airway smooth muscle from asthmatic dogs. Proceedings National Academy of Science, U.S.A., 76, 1472. 
Siraganian, R.P., Kulczyzki, J., MendozA, G. \& Metzger, H. (1975) Ionophore A 23187 induced histamine release from rat mast cells and rat basophil leukemia (RBL-1) cells. Journal of Immunology, $115,1599$.

Smith, L.J., Shelhamer, J.H. \& Kaliner, M. (1980) Cholinergic nervous system and immediate hypersensitivity. II. An analysis of pupillary responses. Journal of Allergy Clinical Immunology, 66, 374.

Smolen, J.E., KorzaK, H.M. \& Weissman, G. (1980) Increased levels of cyclic adenosine-3' $5^{\prime}$ monophosphate in human polymorphonuclear leucocytes after surface stimulation. Journal of Clinical Investigation, 65, 1077.

Stephens, N.L., Mitchell, R.W., Antonissen, L.A., Kromer, U., Hanks, B., Kroeger, E.A. \& Kepron, W. (1980) Airway smooth muscle: physical properties and metabolism. In: Airway Reactivity (ed. F. E. Hargreave) p. 110. McMaster University, Hamilton. 
Copyright of Clinical Allergy: Journal of the British Allergy Society is the property of Blackwell Publishing Limited and its content may not be copied or emailed to multiple sites or posted to a listserv without the copyright holder's express written permission. However, users may print, download, or email articles for individual use. 